\title{
COEFICIENTE FENÓLICO NA AVALIAÇÃO MICROBIOLÓGICA DE DESINFETANTES DE USO HOSPITALAR E DOMÉSTICO
}

Jorge Timenetsky*

Flávio Alterthum*

\begin{abstract}
TIMENETSKY, J. \& ALTERTHUM, F. Coeficiente fenólico na avaliação microbiológica de desinfetantes de uso hospitalar e doméstico. Rev. Saúde públ., S. Paulo, 23:170-4, 1989.

RESUMO: Analisou-se o coeficiente fenólico de 24 desinfetantes comercializados em São Paulo (Brasil). Seis produtos eram de uso hospitalar e os restantes de uso doméstico. Os compostos ativos eram à base de fenóis, amônio quaternário, formaldeído, etanol e cloro, sendo que alguns estavam associados. Os microrganismos utilizados foram Staphylococcus aureus ATCC 6538, Pseudomonas aeruginosa ATCC 15442 e Salmonella choleraesuis ATCC 10708. Os valores dos coeficientes fenólicos variaram de 58,3 a 0,1 . Os desinfetantes hospitalares mostraram valores superiores aos de uso doméstico, mas estas diferenças, proporcionalmente, não significaram melhor qualidade dos mesmos. $O$ método microbiológico adotado mostrou que alguns produtos, de uso doméstico, aparentemente possuiam atividade antibacteriana baixa ou inexistente porque o coeficiente fenólico não pôde ser obtido nas diluições utilizadas na avaliação.
\end{abstract}

DESCRITORES: Desinfetantes. Avaliaçāo.

\section{INTRODUÇÃO}

A metodologia para a verificação do coeficiente fenólico descrito em 1903 por Rideal e Walker, estava originalmente voltada para avaliar e comparar a atividade antibacteriana dos derivados fenólicos naturais do ácido fênico (fenol). O teste era realizado apenas frente a Salmonella typhi, microrganismo de importância epidemiológica?. Atualmente, a metodologia possui os mesmos princípios com o uso de cepas padrões de Staphylococcus aureus, Pseudomonas aeruginosa e Salmonella typhi. O protocolo oficial está atualmente descrito, entre outros, no manual da Association of Official Analytical Chemist (AOAC) para a avaliação microbiológica de desinfetantes químicos ${ }^{1}$. Verifica-se na literatura que o princípio do método foi aplicado não somente aos fenóis naturais e sintéticos, mas para outros compostos ativos frente a outras espécies bacterianas, inclusive esporuladas 6.0 coeficiente fenólico é a razão do inverso de diluiçðes em água do desinfetante em teste e do fenol, que provocam o mesmo efeito deletério sobre as bactérias. O coeficiente fenólico aindà é muito conhecido e divulgado em livros de graduação recentes como sendo, por vezes, o único método de avaliação microbiológica de desinfetantes embora sujcito a críticas 9,15 . Os valores dos coeficientes fenólicos ainda são comparados com a eficácia de um produto, de modo a caracterizar os desinfetantes 2 .

Constatamos que os valorês dos coeficientes fenólicos eram explorados comercialmente; um produto desinfetante com coeficiente fenólico maior do que outro era proclamado pelo fabricante como melhor. Verificamos que os produtos comercialmente disponíveis podem apresentarse em forma de soluções simples ou complexas cujos rótulos nem sempre apresentam claramente as respectivas formulaçōes ou substâncias adicionais como essências, estabilizadores, emulsificantes, anticorrosivos, entre outras.

Poucas foram as divulgações de resultados com os desinfetantes comercializados em nosso meio, para a verificação do coeficiente fenólico, principalmente com produtos de uso doméstico cuja escolha e uso são normalmente arbitrárias e/ou subjetivas ${ }^{3}$.

O objetivo do presente trabalho é verificar o coeficiente fenólico da AOAC como método de avaliação microbiológica de soluçōes de desinfetantes comercialmente disponíveis para uso hospitalar e doméstico.

Departamento de Microbiologia do Instituto de Ciĉncias Biomédicas da Universidade de São Paulo - Av. Prof. Lineu Prestes, 1374 - 05508 - São Paulo, SP - Brasil. 


\section{MATERIAL}

\section{Microrganismos}

Staphylococcus aureus ATCC 6538, Pseudomonas aeruginosa ATCC 15442 e Salmonella choleraesuis ATCC 10708.

Meios de cultura para cultivo, subcultivo e manutenção das bactérias ${ }^{1}$ : Caldo nutriente (DIF$\mathrm{CO})$ duplamente concentrado e adicionado $0,5 \%$ de $\mathrm{NaCl}$. Agar Nutriente - Caldo Nutriente adicionado de 1,5\% de agar (bacto-agar-Difco). Agar Cistina Tripticase(BBL), para manutenção de Pseudomonas aeruginosa.

Outros materiais: Tubos ( $25 \times 250 \mathrm{~mm})$ (1), alça bacteriológica padronizada com $4 \mathrm{~mm}$ de diâmetro (1), Banho Maria à $20^{\circ} \mathrm{C}$ (1), agitador de tubos tipo Vortex.

Desinfetantes: (1-6 Hospitalares), (7-24 uso doméstico).

1. Tersyl (fenóis sintéticos)

2. Markofen (fenóis sintéticos)

3. Duplofen (fenóis sintéticos)

4. Duocide (formaldeído amônio quaternário + etanol)

5. Germekil (amônio quaternário)

6. Cidex (glutaraldeído)

7. Harpic-WC (amônio quaternário)

8. Sanpic pinho (amônio quaternário)

9. Cleosol (amônio quaternário)

10 Kalipto (Fenol + amônio quaternário)

11. Pinho Bril (fenóis sintéticos)

12. Pinho White (fenóis sintéticos)

13. Pinho Sol (fenóis sintéticos)

14. Tok Pinho (fenóis sintéticos)

15. Whitak (fenol sintético + formaldeído)

16. White (fenol sintético + formaldeído)

17. Lysoform bruto (formaldeído)

18. Fanny - Eucalipto (formaldeído)

19. Fan - Lavanda (formaldeído)

20. Fan - Jasmin (formaldeído)

21. Pinho Lider (formaldeído)

22. Desinfetante (formulação não especificada)

23. Álcool Zulu (álcool etílico)

24. Super Cândida (hipoclorito)

\section{MÉTODO}

Baseou-se em metodologia descrita no manual da $A O A C^{1}$. Seguiram-se as seguintes modificações:

a) Salmonella choleraesuis no lugar de Salmonella typhi;

b) não foram adicionados inativadores de desinfetantes nos subcultivos;

c) não foi adicionado matéria orgânica nos tubos teste $(0,5 \mathrm{ml}$ de caldo bacteriano de $24 \mathrm{~h}$ à $37^{\circ} \mathrm{C}+5,0 \mathrm{ml}$ da solução do desinfetante).
Experimento controle: a) confirmação das bactérias (estafilococos, pseudomonas e salmonella) quando recuperados dos tubos teste ${ }^{1}$; b) controle da interferência de resíduos de desinfetantes carreados para os subcultivos através da alça padronizada.

\section{RESULTADOS E DISCUSSÃO}

Cada produto possui três valores de coeficiente fenólico, correspondente à sensibilidade intrínseca de cada espécie bacteriana utilizada. As maiores diluições do fenol $(5,0 \%)$, necessúrias para a recuperação de bactérias em $5 \mathrm{~min}$. mas não em 10, foram de 1/90 frente Staphylococcus aureus, 1/110 frente Pseudomonas aeruginosa e $1 / 100$ frente Salmonella choleraesuis. $O$ inverso das maiores diluições dos produtos desinfetantes testados, que provocaram o mesmo efeito deletério, foram divididos pelo inverso das diluiçбes do fenol acima citadas.

$\mathrm{Na}$ verificação da interferência dos resíduos dos desinfetantes carreados para os tubos de subcultivo, observamos que estes não interferiram nos resultados. Neste experimento controle, todos os tubos controle em triplicata (uma alçada do cultivo bacteriano de $24 \mathrm{~h}$ à $37^{\circ} \mathrm{C}+$ uma alçada do desinfetante não diluído em $15,0 \mathrm{ml}$ de caldo nutriente), permitiram a recuperação das três espécies bacterianas em experimentos separados.

Os valores dos coeficientes fenólicos dos produtos estão expressos em escala logarítmica na Figura, pois os resultados variaram de 58,3 a 0,1 , que é o menor valor possível de ser calculado em nosso experimento devido à seqüência de diluiçð̃es utilizadas.

Verificamos, em outros trabalhos, que os citados produtos, números $1,2,3,4,5,6,7,8,11,14$, 17,23 e 24 , quando em contato com as mesmas bactérias por 15 segundos permitiram revelar a redução de cinco ciclos logarítmicos, na maioria das diluiçōes recomendadas para o uso ${ }^{13,14}$.

Desta maneira, o valor do coeficiente fenólico dos produtos do presente trabalho não podem representar proporcionalmente sua eficácia, assim a comparaçăo pode ser apenas relativa e não absoluta.

Assim, por exemplo, o desinfetante número 2 (Markofen) com coeficiente fenólico de 20,0 para Staphylococcus aureus, 3,6 para $P_{\text {seudomo- }}$ nas aeruginosa e 14,5 para Salmonella choleraesuis não é necessariamente melhor que o produto número 8 (Sanpic Pinho) com valores de coeficionte fenólico de $7,2,1,4$ e 4,0 respectivamente, para as mesmas bactérias. $\mathrm{Na}$ realidade o que importa é a atividade antibacteriana da diluição recomendada para o uso do produto. $\mathrm{O}$ 


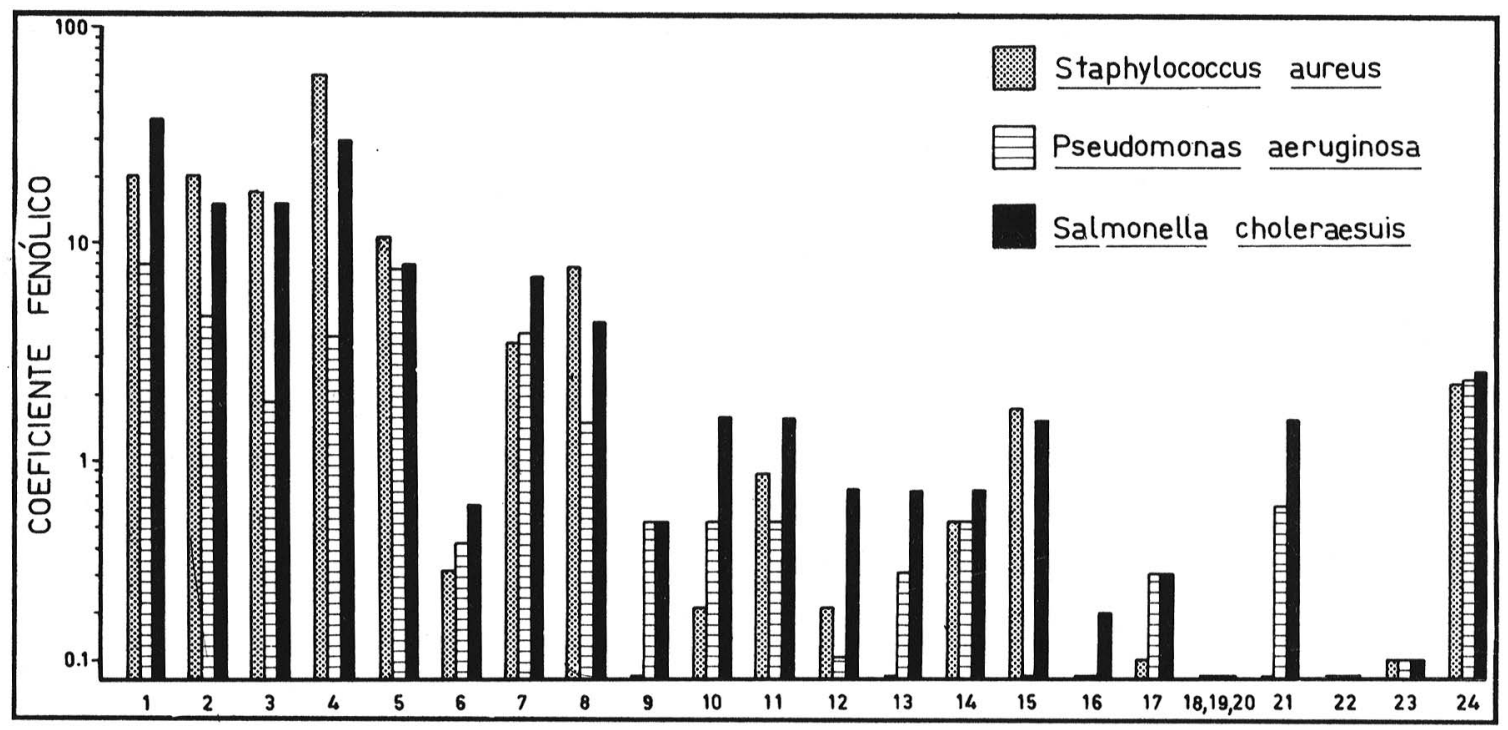

Fig. - Coeficiente fenólico dos desinfetantes de uso hospitalar (1-6) e de uso doméstico (7 a 24$)$.

primeiro produto exemplificado precisou ser mais diluído que o segundo para provocar o mesmo efeito deletério, de acordo com as instruções da embalagem.

Ortobenzil-paraclorofenol, um dos fenóis sintéticos usados mais freqüentemente em desinfetantes hospitalares e domésticos, a partir de seu estado maiș puro, possui coeficiente fenólico de 200,0 frente Staphylococcus aureus ${ }^{10}$, já o álcool etílico frente à mesma espécie bacteriana possui coeficiente fenólico de 0,049 .

A concentração e o coeficiente de diluição em água ${ }^{12}$ do(s) composto(s) ativo(s) são os principais fatores na variação dos valores do coeficiente fenólico. Não podemos descartar que os fatores inerentes da própria metodologia, a adição de essências, estabilizadores, antioxidantes e outras substâncias desconhecidas e as formulações, diferentes das descritas nos rótulos, possam interferir nos resultados desta metodologia. Assim, produtos aparentemente idênticos, como no caso dos produtos de número 1 (Tersyl) e 2 (Markofen), possuem coeficientes fenólicos diferentes. Esses produtos possuem igualmente ortobenzil-paraclorofenol $(4,125 \%)$ e paraterciário butil fenol $(3,0 \%)$, porém as diluições recomendadas para uso são diferentes $(3,0 \%$ ou $1,0 \%$ para 0 primeiro e $4,3 \%$ ou $5,0 \%$ para o segundo).

Apesar do valor do coeficiente fenólico não caracterizar a eficácia de um produto comercializado, era convertido numa diluição prática para uso, multiplicado por 20 (correspondente ao fenol à $5,0 \%$ ). Esta conduta não é mais recomendada, principalmente para os desinfetantes cujos compostos ativos não são fenólicos ou sensíveis à matéria orgânica 4 . Se esta conversão fosse realizada para os produtos que analisamos, as diluições resultantes seriam superiores a algumas recomendações de seus rótulos, com exceção dos produtos de número ${ }^{14}$ (Tok Pinho - 1/30), 17 (Lysoform Bruto à 1/80), 24 (Super Cândida à 1/80), 22 (Desinfetante) e 23 (Álcool Zulu), estes dois últimos sem orientação para o uso.

A maioria dos produtos de uso doméstico não deve ser diluída para uma ação desinfetante, enquanto os hospitalares podem ser muito diluídos, de $2 \%$ a $5 \%$; porém, não os produtos de números 5 (Germekil) e 6 (Cidex).

Como os produtos de uso doméstico estão mais sujeitos ao uso e escolha arbitrária e/ou subjetiva, estariam portanto, mais sujeitos a perderem seus espectros de atividade antibacteriana do que os hospitalares, pois as oscilações numéricas de seus repectivos coeficientes fenólicos estão mais próximos entre si do que os de uso hospitalar, em sentido absoluto.

Apesar das limitações da interpretação dos resultados da metodologia para a verificação do coeficiente fenólico, pode, entretanto, aparentemente revelar produtos com atividade antibacteriana mais reduzida ou mesmo inexistente. Assim, temos os produtos de número 9 (Cleosol) e 13 (Pinho Sol), frente a cepa de estafilococo, e 18 (Fanny-Eucalipto), 19 (FanLavanda) e 20 (Fan-Jasmin), que mesmo não diluídos permitiram a recuperação das bactérias aos 5,10 e/ou $15 \mathrm{~min}$, não permitindo a verificação do coeficiente fenólico. Os produtos 
números $18,19,20$ são do mesmo fabricante possuindo formaldeído à $2,0 \%$, mas com essências aromáticas diferentes.

A verificação do coeficiente fenólico é uma avaliação qualitativa e a turvação observada em alguns tubos pode ser originária de uma ou mais células. A metodologia por nós adaptada, anteriormente comentada ${ }^{14}$, revelou que os produtos 18,19 e 20 , apusar de não permitirem a verificação do cocticiente fenólico, revelaram a capacidade de diminuir em 5 min., dois ciclos logarítmos da população de células da cepa de salmonela, quando não diluídos.

A cepa de Salmonella choleraesuis foi incluída na presente pesquisa porque fez parte das 3 espécies bacterianas utilizadas em trabalhos anteriores ${ }^{13,14}$, utilizando-se métodos diferentes de avaliaçăo microbiológica de desinfetantes com os mesmos produtos.

Atualmente as 3 espécies do presente trabatho fazem parte de uma das metodologias (diluição uso - AOAC) recentemente adotada no Brasil para avaliação microbiológica de desinfe- tantes para efeito de registro 5,7. A avaliação através desta metodologia também possui princípios qualitativos e a sua reprodutibilidade, atualmente, é bastante discutida ${ }^{8}$.

Devemos, portanto, analisar também com cautela os resultados da verificação do coeficiente fenólico embora seja um método oficial. Apesar de existirem outros métodos e entidades oficiais que preconizam diferentes protocolos de avaliação microbiológica de desinfetantes, não existe um único aceito por todos ${ }^{11}$.

Desta maneira, um produto desinfetante pode ser aprovado num país e ser rejeitado em outro, pois cada país adota uma ou outra metodologia. Esta situação não parece ser de resolução breve, sendo necessário que se realizem determinações e análises de maior amplitude.

Concluindo, os produtos desinfetantes de uso hospitalar e doméstico possuem coeficientes fenólicos bem diferentes, mas mesmo assim, não podem ser comparados quanto à sua eficácia germicida.

TIMENETSKY, J. \& ALTERTHUM, F. [The phenolic coefficient in microbiological evaluation of disinfectants for hospital and household use]. Rev. Saúde públ., S. Paulo, 23:170-4, 1989.

ABSTRACT: The phenolic coefficient of 24 disinfectants (six for hospital and the remainder for household use) commercialized in S. Paulo were verified. The active compounds found were phenol, quaternary ammonium, formaldehyde, ethanol and chlorine, some of then in association. The microorganisms used were Staphylococcus aureus ATCC 6538, Pseudomonas aeruginosa ATCC 15442 and Salmonella choleraesuis ATCC 10708. The values of the phenolic coefficient ranged from 58.3 to 0.1. The hospital disinfectants showed values greater than those of the disinfectants for household use, though these differences do not necessarily indicate the quality of the respective products. Conversely the microbiological method adopted showed that some products for household use had low or inexistent antibacterial activity because the phenolic coefficient could not be determined for the dilutions used for this evaluation.

KEYWORDS: Disinfectants, analysis. Evaluation. 


\section{REFERÊNCIAS BIBLIOGRÁFICAS}

1. ASSOCIATION OF OFFICIAL ANALYTICAL CHEMIST. Official methods of analysis. 14th ed. Arlington, 1984. p. 65-8.

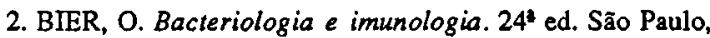
Melhoramentos/Ed. USP, 1985.

3. RLOOMFIELD, S.F. The use of disinfectants in home: a review. J. appl. Bacteriol., 45: 1-38, 1978.

4. CROSHAW, B. Disinfectant testing. In: Collins, C.H.; Allowood, D.M.C.; Bloomfield, S.F.; Fox, A., eds. Disinfectants: their use and evaluation of effectiveness. New York, Academic Press, 1981. (Society for Applied Bacteriology Technical Series, $\left.n^{2} 16\right)$.

5. INSTTTUTO NACIONAL DE CONTROLE DE QUALIDADE EM SAUUDE. Técnicas para controle de qualidade; avaliação da atividade antibacteriana de saneantes domis. satários. Rio de Janeiro, Fundação Oswaldo Cruz, 1985. (Manual Técnico $n^{2}$ 04/85).

6. LAWRENCE, C.A. Antimicrobial activity "in vitro" of Clothexidine. JAmer.pharm.Ass., 49: 731-4, 1960.

7. MINISTÉRIO DA SAUDDE. Portaria $n^{\circ} 67$ de 21 de fevereiro de 1985. Diário Oficial da Uniâo, Brasília, 27 fev. 1985. Sec. $1 / 3181$.

8. MYERS, T. Failing the test: germicides or use dilution methodology? Amer.Soc.Microbiol.News, 54(1): 19-21, 1988.

9. PELCZAR, M.; REID, R.; CHAN, E.C.S. Microbiologia. São Paulo, McGraw Hill do Brasil, 1980. v. 1, p. 494516.
10. PRINDLE, R.F. Phenolic compounds. In: Block, S.S., ed. Disinfection sterilization and preservation. Philadelphia, Lea \& Febiger, 1983. p. 197-219.

11. REYBROUCK, G. The evaluation of the antimicrobial activity of disinfectants. In: Russel, A.D.; Hugo, W.B.; Ayliffe, G.A.J., eds. Principles and practice of disinfection, preservation and sterilization. London, Blackwell, 1982. p. 134-55.

12. RUSSEL, A.D. Factors influencing the efficacy of antimicrobial agents. In: Russel, A.D.; Hugo, W.B.; Ayliffe, G.A.J., eds. Principles and practice of disinfection, preservation and sterilization. London, Blackwell, 1982. p. 107 28.

13. TIMENETSKY, J. Avaliação antibacteriana de desinfetantes químicos de uso hospitalar e doméstico. São Paulo, 1987. [Tese de Doutorado - Instituto de Ciências Biomédicas da USP].

14. TTMENETSKY, J. \& ALTERTHUM, F. Determinação da atividade antibacteriana de desinfetantes domésticos. Rev. Microbiol., S. Paulo, 19(1): 46-51, 1988.

15. WISTREICII, G.A. \& LECITMAN, M.D. Microbiologia das doenças humanas. 2 ed. Sāo Paulo, GuanabaraKoogan, 1980.
Recebido para publicaçāo em 18/7/1988 Reapresentado em 30/1/1989 Aprovado para publicação em 10/2/1989 